\title{
Differentiating between visual hallucination-free dementia with Lewy bodies and corticobasal syndrome on the basis of neuropsychology and perfusion single-photon emission computed tomography
}

\author{
Michael R Misch', Sara Mitchell ${ }^{1}$, Philip L Francis ${ }^{1}$, Kayla Sherborn $^{1}$, Katayoun Meradje ${ }^{1}$, Alicia A McNeely ${ }^{1}$, \\ Kie Honjo ${ }^{1}$, Jiali Zhao ${ }^{1}$, Christopher JM Scott ${ }^{1}$, Curtis B Caldwell ${ }^{2}$, Lisa Ehrlich ${ }^{3}$, Prathiba Shammi ${ }^{4}$, \\ Bradley J Maclntosh', Juan M Bilbao ${ }^{5}$, Anthony E Lang ${ }^{6}$, Sandra E Black ${ }^{1,7}$ and Mario Masellis ${ }^{1,7,8,9^{*}}$
}

\begin{abstract}
Introduction: Dementia with Lewy bodies (DLB) and Corticobasal Syndrome (CBS) are atypical parkinsonian disorders with fronto-subcortical and posterior cognitive dysfunction as common features. While visual hallucinations are a good predictor of Lewy body pathology and are rare in CBS, they are not exhibited in all cases of DLB. Given the clinical overlap between these disorders, neuropsychological and imaging markers may aid in distinguishing these entities.

Methods: Prospectively recruited case-control cohorts of CBS $(n=31)$ and visual hallucination-free DLB $(n=30)$, completed neuropsychological and neuropsychiatric measures as well as brain perfusion single-photon emission computed tomography and structural magnetic resonance imaging (MRI). Perfusion data were available for forty-two controls. Behavioural, perfusion, and cortical volume and thickness measures were compared between the groups to identify features that serve to differentiate them.

Results: The Lewy body with no hallucinations group performed more poorly on measures of episodic memory compared to the corticobasal group, including the delayed and cued recall portions of the California Verbal Learning Test $(F(1,42)=23.1, P<0.001$ and $F(1,42)=14.0, P=0.001$ respectively) and the delayed visual reproduction of the Wechsler Memory Scale-Revised ( $F(1,36)=9.7, P=0.004)$. The Lewy body group also demonstrated reduced perfusion in the left occipital pole compared to the corticobasal group $(F(1,57)=7.4, P=0.009)$. At autopsy, the Lewy body cases all demonstrated mixed dementia with Lewy bodies, Alzheimer's disease and small vessel arteriosclerosis, while the corticobasal cases demonstrated classical corticobasal degeneration in five, dementia with agyrophilic grains + corticobasal degeneration + cerebral amyloid angiopathy in one, Progressive Supranuclear Palsy in two, and Frontotemporal Lobar Degeneration-Ubiquitin/TAR DNA-binding protein 43 proteinopathy in one. MRI measures were not significantly different between the patient groups.

(Continued on next page)
\end{abstract}

\footnotetext{
* Correspondence: mario.masellis@sunnybrook.ca

${ }^{1}$ L.C. Campbell Cognitive Neurology Clinic, Sunnybrook Health Sciences Centre, Room A4 42, 2075 Bayview Avenue, Toronto, ON M4N 3M5, Canada ${ }^{7}$ Department of Medicine (Neurology), Brain Sciences Research Program, Sunnybrook Health Sciences, Centre University of Toronto, Room A4 42, 2075 Bayview Avenue, Toronto, ON M4N 3M5, Canada

Full list of author information is available at the end of the article
} 
(Continued from previous page)

Conclusions: Reduced perfusion in the left occipital region and worse episodic memory performance may help to distinguish between DLB cases who have never manifested with visual hallucinations and CBS at earlier stages of the disease. Development of reliable neuropsychological and imaging markers that improve diagnostic accuracy will become increasingly important as disease modifying therapies become available.

\section{Introduction}

Dementia with Lewy Bodies (DLB) and Corticobasal Syndome (CBS) are atypical parkinsonian disorders associated with fronto-subcortical and posterior cognitive dysfunction. Pathologically, DLB is an $\alpha$-synucleinopathy with many cases having concomitant Alzheimer's pathology [1]. $\mathrm{CBS}$ is more heterogeneous with the following underlying pathological substrates observed: corticobasal degeneration (CBD) , progressive supranuclear palsy (PSP), frontotemporal lobar degeneration (FTLD)-Tau (Pick's disease) and FTLD-Ubiquitin/TAR DNA binding protein (TDP43), Alzheimer's disease (AD) and, rarely, DLB [2-6]. In a small case series of pathologically proven $\mathrm{CBD}$, one patient had a differential diagnosis of CBS versus DLB and was eventually confirmed to have CBD at autopsy [7]. Clinically, DLB is characterized by recurrent visual hallucinations, spontaneous parkinsonism, fluctuating attention and alertness as well as executive and visuospatial dysfunction $[8,9]$. 'Classical' CBS is characterized by asymmetric rigidity, apraxia, dystonia, myoclonus, alien-limb phenomenon and/or cortical sensory loss [10]; however, dementia is often the initial presentation and classical features may emerge only later in the disease course [11]. While the two disorders can usually be distinguished on clinical grounds in the mid-stages of the disease course, the early stages often have overlapping clinical features and accurate diagnosis is more challenging especially when not all features are present.

The diagnostic criteria for DLB have demonstrated greater specificity (95\%) than sensitivity (83\%) [12]; other studies have reported even less successful figures $[13,14]$. While visual hallucinations are exceptionally rare in CBS [15], they have been shown to be the most sensitive and specific predictor of DLB pathology [16]. However, the prevalence of visual hallucinations ranges between $30 \%$ to $80 \%$ of pathologically proven DLB cases, indicating a low negative predictive value [9]. Recognizing and diagnosing DLB presenting without visual hallucinations early on and distinguishing it from CBS and other atypical parkinsonian syndromes has direct clinical relevance. For example, the symptoms of DLB have been shown to respond well to cholinesterase inhibitors $[17,18]$, while patients with frontotemporal dementia spectrum disorders that includes CBS, do not benefit cognitively and may be more prone to behavioural disturbance on this class of drugs [19]. As such, additional data made available by neuroimaging and neuropsychological assessment may help to best differentiate DLB without visual hallucinations from CBS and this could allow clinicians to better target symptomatic therapy and avoid unwanted side effects. Furthermore, understanding differences between these two parkinsonian disorders using neuroimaging and neuropsychological evaluation may also shed light onto pathological correlates.

The objectives of this study were to compare: 1 ) the initial clinical and standardized neuropsychological and neuropsychiatric profile of a prospective cohort of 30 DLB patients with no history of visual hallucinations (visual hallucination-free [VHF]-DLB) and 31 CBS patients ascertained from both a movement disorders clinic and a cognitive neurology clinic; and 2) the perfusion single-photon emission computed tomography (SPECT) and structural magnetic resonance imaging (MRI) imaging features of CBS and VHF-DLB patients to elucidate functional and structural imaging findings that most reliably distinguish the two groups.

\section{Methods \\ Participants}

Thirty participants meeting clinical criteria for possible $(\mathrm{n}=10)$ or probable DLB $(\mathrm{n}=20)$ [9] without any history of visual hallucinations were recruited through the Linda C. Campbell Cognitive Neurology Research Unit at Sunnybrook Health Sciences Centre. Thirty-one participants with a clinical diagnosis of CBS according to diagnostic criteria proposed by Boeve et al. [20] were recruited through the former clinic and the Movement Disorders Centre at the Toronto Western Hospital, University Health Network. Diagnoses were made by consensus agreement by at least two reviewing neurologists with expertise in neurodegenerative diseases (MM, AEL and/or SEB). This study also included 42 healthy controls with available SPECT data; 30 of them were matched to the VHF-DLB group (11 were unique to this group and 19 overlapped with the CBS control group) while 31 were matched to the CBS group (12 were unique to this group and 19 overlapped with the VHF-DLB control group). Controls were selected to match as closely as possible for age, sex and years of education for each patient group. Subjects had to have a SPECT scan completed and available for analysis to be included in the study. Subjects needed to be within the age range of 40 to 90, have contact with a primary caregiver on at least four days per week, were sufficiently literate and fluent in 
English, and their SPECT and neuropsychological evaluations were completed within a consecutive three-month period. Exclusion criteria were: presence of secondary/ reversible causes of dementia which were untreated, concomitant neurological or psychiatric illness/substance use and abuse, history of significant head trauma, as well as lesions on MRI indicating another pathological condition. The majority of the VHF-DLB, CBS and normal controls were recruited and monitored as part of the Sunnybrook Dementia Study (ClinicalTrials.gov identifier: NCT01800214), a prospective longitudinal study of dementia and ageing. Seven of the VHF-DLB patients were recruited through a prospective pharmacogenetic study of cholinesterase inhibitor response in Lewy body spectrum disorders (ClinicalTrials.gov identifier: NCT01944436), which employed similar imaging and clinical assessments as the Sunnybrook Dementia Study. Both studies were approved by the local Research Ethics Boards at Sunnybrook Health Sciences Centre and the Toronto Western Hospital, University Health Network. Written informed consent was obtained from the participants or their substitute decision makers in accordance with the Declaration of Helsinki.

\section{Neuropsychological, neuropsychiatric and functional measures}

Neuropsychological tests assessing general intelligence and cognition included Folstein's Mini-Mental State Examination (MMSE) [21]; the Mattis Dementia Rating Scale (DRS) [22]; the Clock Drawing Test [23]; the National Adult Reading Test-Revised (NART-R) [24]; and Raven's Progressive Matrices [25]. Tests assessing learning and episodic verbal memory included the California Verbal Learning Test (CVLT) [26], while the visual reproduction subtest of the Wechsler Memory Scale-Revised (WMS-R) assessed visual memory [27]. Measures of language function and naming included: the Boston Naming Test (BNT) [28]; semantic/categorical fluency [29]; and the comprehension subscale of the Western Aphasia Battery (WAB) [30]. Initially, the full WAB was given to all patients, but in the last few years it has only been administered if there was anomia detected on the BNT [30]. Facial and limb praxis was assessed using the WAB praxis subscale [30]. Attention and working memory was assessed using the Forward and Backward Digit Span tests from the WMS-R [27,31]. Several assessments of executive function were employed including: phonemic (F-, A-, and S-word) fluency [27,29]; the Trail Making Test A and B (TMT-A and -B) [27]; and the Wisconsin Card Sort Test (WCST) [32]. Visuospatial function was assessed using the Rey-Osterrieth Complex Figure Test $[27,33,34]$ and the Benton Line Orientation task, which is motor-free and assesses visuospatial orientation and attention [27]. Behavioural function was investigated using the Neuropsychiatric Inventory (NPI-12) [35]. Severity of depressive symptoms was assessed using the
Cornell Scale for Depression in Dementia (CSDD) [36]. Functional assessment was performed using the Disability Assessment for Dementia (DAD), which assesses both basic and instrumental activities of daily living including subcomponents of initiation, planning and performance [37].

\section{Brain SPECT acquisition and processing}

SPECT imaging employed a triple-head gamma camera (Prism 3000XP; Phillips Medical Systems Inc., Cleveland, $\mathrm{OH}, \mathrm{USA}$ ) and was performed between 30 and 120 minutes after injection of $20 \mathrm{mCi}(740 \mathrm{MBq})$ of Technetium-99 m ethyl cysteinate dimer (99mTc-ECD SPECT). Patients were asked to rest with their eyes open during the injection phase in a quiet room. A total of 120 views were acquired uniformly over 360 degrees using all three detectors fitted with ultra-high resolution fan-beam collimators. Each view consisted of a $128 \times 128$ pixel image. Imaging time was 19 minutes. A ramp-filtered back-projection algorithm followed by a three-dimensional restoration post-filter was employed for image reconstruction (Wiener filter, multiplier 1.0). Reconstructed image resolution was $9.7 \mathrm{~mm}$ full width at half maximum (FWHM). Ellipses were fit to the approximate location of the head outline in each transaxial image and a calculated attenuation correction applied [38]. Voxel dimensions were $2.18 \times 2.18 \times 3.56 \mathrm{~mm}$.

\section{Brain MRI acquisition, processing and region of interest cortical volumetric/thickness assessment MRI acquisition}

Structural MRI was obtained in 29 of the 31 CBS patients and 25 of the 30 VHF-DLB patients using a standard protocol. Images were acquired on a 1.5 T Signa MR imager (GE Medical Systems, Milwaukee, WI, USA) and consisted of the following acquisitions: 1) T1-weighted (axial threedimensional spoiled gradient (SPGR) echo, with echo time (TE) $5 \mathrm{~ms}$, repetition time (TR) $35 \mathrm{~ms}$, flip angle $35^{\circ}$, number of excitations (NEX) 1, field of view (FOV) $22 \times$ $16.5 \mathrm{~cm}$, in-plane resolution $0.859 \times 0.859 \mathrm{~mm}$ and slice thickness 1.2 to $1.4 \mathrm{~mm}$ ); 2) proton-density (PD); and 3) T2-weighted images (interleaved axial spin echo, with TEs 30 and $80 \mathrm{~ms}$, TR $3 \mathrm{~s}$, NEX 0.5, FOV $20 \times 20 \mathrm{~cm}$, in-plane resolution $0.781 \times 0.781 \mathrm{~mm}$ and slice thickness $3 \mathrm{~mm}$ ).

\section{Brain extraction and automated tissue segmentation}

Twenty-one of the 29 CBS scans and 23 of the 25 VHFDLB scans were of sufficient quality to undergo semiautomated image analysis. Poor image quality was primarily due to head motion artifacts. Brain extraction and automated tissue segmentation were based on previously described methods $[39,40]$. Images were co-registered to the T1-weighted image using the Functional Magnetic Resonance Imaging of the Brain (FMRIB) Software Library's (FSL) flirt tool and a normalised mutual information cost function [41]. Proton density (PD)/T2 images were used 
collectively to extract brain and subdural/ventricular cerebrospinal fluid (CSF), then the masked T1 was segmented using a T1-based protocol whereby local intensity histograms are fitted to four Gaussian curves to derive cut-offs for classifying each voxel as white matter, grey matter or CSF [39]. This is important for calculating the total intracranial volume in correcting for head size, especially in focal atrophy syndromes, such as CBS. Lesion Explorer was then used to further segment tissue that appears hyperintense on PD and T2 and a trained rater manually checked the lesion mask and corrected false positives/negatives [40]. This lesion mask was then overlaid onto the segmented brain to identify the four lesion classes (periventricular subcortical hyperintensities and black holes, as well as deep subcortical hyperintensities and black holes) based on three-dimensional location and T1 intensity [40].

\section{FreeSurfer cortical thickness and volume calculations}

The FreeSurfer cortical parcellation procedure was subsequently applied to the fully segmented Lesion Explorer scans. The boundary between white and grey matter was corrected for topological defects [42] and deformed outward in order to locate the pial surface and achieve the final thickness estimations [43]. A region of interest (ROI) gyral atlas was then applied to obtain cortical thickness $(\mathrm{mm})$ and volume $\left(\mathrm{mm}^{3}\right)$ measurements in 34 bilateral gyral ROIs [44].

\section{Statistical parametric mapping SPECT analysis}

SPECT scans were converted to Analyze 7.5 format. Statistical Parametric Mapping version 5 (SPM5, Wellcome Department of Imaging Neuroscience, University College London, London, UK) was used for all imaging processing. Images were spatially normalised to a standard SPECT template in Montreal Neurological Institute (MNI) space [45] with re-sampling of voxel dimensions of $2 \times 2 \times$ $2 \mathrm{~mm}$. Images were then smoothed spatially using an isotropic Gaussian kernel (12 mm FWHM). Proportional scaling was used to normalise image intensity values between subjects, thus reducing the chances that intersubject variability in cerebral tracer uptake would influence regional perfusion changes. The cerebellum is frequently used to normalise SPECT counts in studies of dementia [45] and was shown to be the region of choice for normalisation in DLB and AD [46]. However, crossed cerebellar diaschisis may lead to relative differences in perfusion between the left and right cerebellar hemispheres, and if the whole cerebellum is used as the reference region in these cases, regional cerebral blood flow ( $\mathrm{rCBF}$ ) may be miscalculated. We, therefore, applied the following rule: if there was more than a $5 \%$ difference in counts between left and right cerebellar hemispheres, the hemisphere with the higher perfusion count was used as the reference region. If the hemispheric difference was less than $5 \%$ then the average count in the whole cerebellum was used as the reference region.

Voxel-by-voxel analyses were performed using unpaired t-tests to compare CBS to controls, and VHFDLB to controls. Covariates were incorporated if they were found to be significantly different between groups. We reported significance using a voxel-wise $P$-value threshold $(P<0.05)$ corrected for multiple comparisons and an extent threshold of at least 20 contiguous voxels $\left(k_{E} \geq 20\right)$. Our correction methodologies included controlling the family-wise error (FWE) rate [47] and controlling the false discovery rate (FDR) [48]. Controlling the FWE rate is more conservative, but is known to be associated with type II errors. A whole brain mask was used to exclude extracranial voxels from the analysis. The maximal peak coordinates of the perfusion differences were converted to Talairach space using the Yale Non-linear MNI to Talairach Converter [49,50]. These converted coordinates were translated into anatomical brain regions and Brodmann Areas (BAs) using Talairach Daemon Client $[51,52]$.

\section{Region of interest SPECT method}

The second phase of the SPECT imaging analyses set out to identify regions of perfusion difference between the VHF-DLB group and the CBS group. A ROI analysis was performed using selected candidate brain regions that were found to show reduced perfusion in the case versus control analysis, but that did not overlap between the CBS and VHF-DLB groups (Figure 1). Reconstructed SPECT images were co-registered to a template that was an average of 14 healthy, elderly control scans. A T1-weighted MRI with dimensions similar to the SPECT template was the source of 79 bilateral ROIs as previously described [53]. To obtain ROI intensity values, we used a common transformation to move from the SPECT template space to MRI space. The cerebellum was used as the reference region in a manner similar to that described in the SPM analysis to generate semi-quantitative perfusion ratios in each ROI [53].

\section{Demographic, clinical, neuropsychological, SPECT ROI and} MRI ROI cortical volumetric and thickness data analysis

Statistical analysis of demographic, clinical, neuropsychological and ROI SPECT variables was performed using the Statistical Package for the Social Sciences (SPSS), version 16. Categorical demographic and clinical data were analysed using chi-square or Fisher exact tests. The normality of continuous demographic, neuropsychological and ROI SPECT and MRI data was assessed based on examination of Q-Q probability plots. Normally distributed data were analysed using independent sample t-tests or univariate analysis of covariance (ANCOVA). Mann Whitney U tests were performed for non-normally distributed data. 


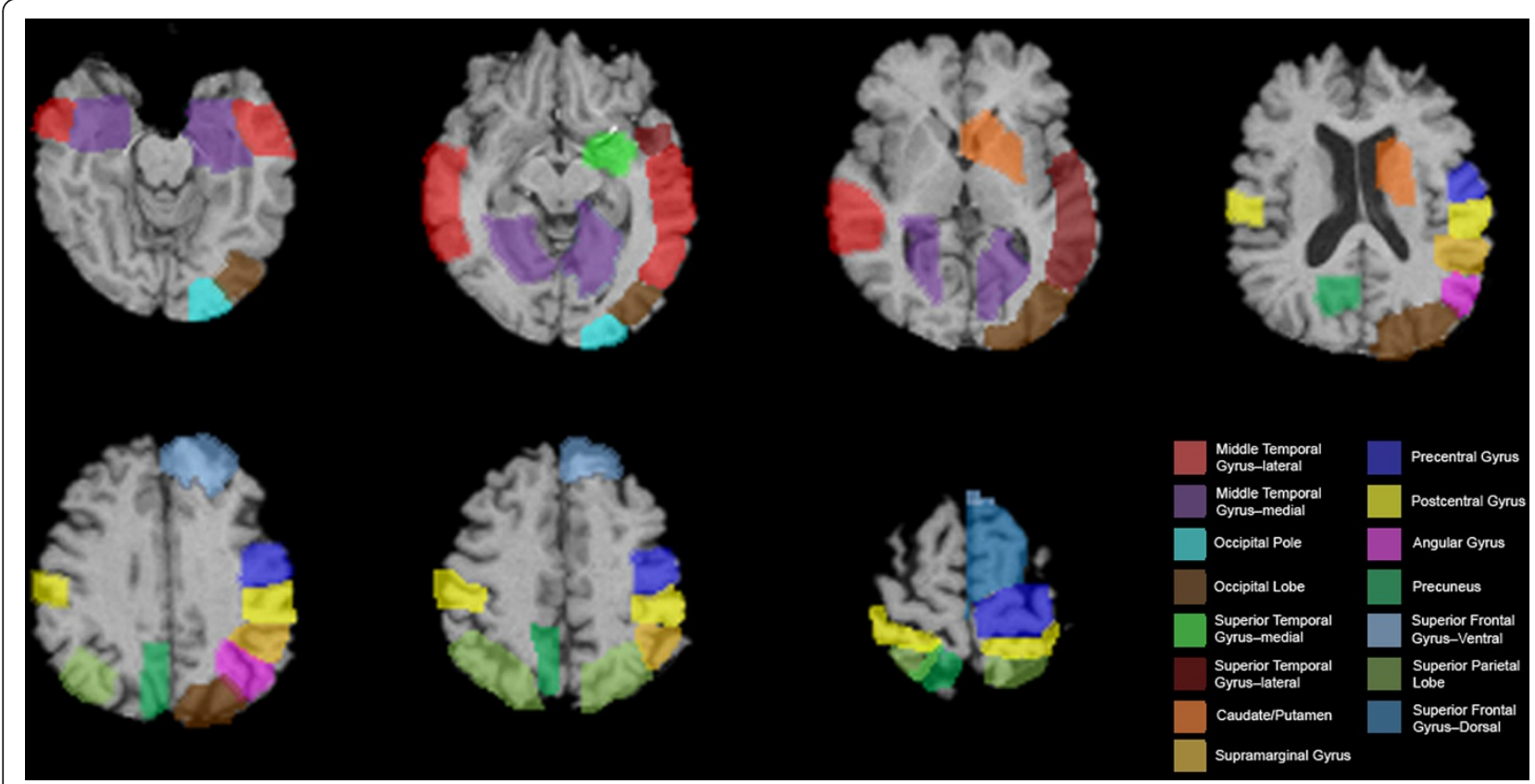

Figure 1 Regions of interest (ROIs) that show differential perfusion in the case versus control analyses. Views are shown in standard radiological orientation.

\section{SPECT analysis}

Multivariate ANCOVA (MANCOVA) was used to compare perfusion ratios within the identified candidate ROIs between the VHF-DLB and CBS groups. Covariates were included if they were found to be different between the groups being compared. We subsequently performed an SPM analysis comparing the VHF-DLB group to the CBS group to confirm the findings of our ROI approach.

\section{MRI analysis}

Independent samples t-tests were performed with cortical ROI volumes and thickness included as dependent variables and with group (that is, CBS versus VHF-DLB) as the independent variable. ROI volume and thickness measurements that showed significant between group differences on the $t$ tests were then incorporated into a MANCOVA model as dependent variables and with group (that is, CBS versus VHF-DLB) as the independent variable. The following covariates were included: sex, years of education and total intracranial volume. A post-hoc Bonferroni correction procedure was applied to adjust for effects of multiple testing.

\section{Logistic regression analysis}

Neuropsychological and imaging measures that were found to be different between the CBS and VHF-DLB groups were then entered as independent variables into a logistic regression model with group membership as the dependent variable.

\section{Pathological assessment}

Three DLB and nine CBS cases came to autopsy. The brains were prepared according to standard neuropathologic

Table 1 Demographics of patients with corticobasal syndrome (CBS), non-hallucinating dementia with Lewy bodies (VHF-DLB) and respective matched control groups

\begin{tabular}{|c|c|c|c|c|}
\hline Demographic and clinical features & $\begin{array}{l}\text { CBS } \\
\text { (number =31) }\end{array}$ & $\begin{array}{l}\text { CBS controls } \\
\text { (number =31) }\end{array}$ & $\begin{array}{l}\text { VHF-DLB } \\
\text { (number =30) }\end{array}$ & $\begin{array}{l}\text { VHF-DLB controls } \\
\text { (number }=30 \text { ) }\end{array}$ \\
\hline Gender & $19 \mathrm{~F} 12 \mathrm{M}^{\mathrm{a}}$ & $19 F 12 \mathrm{M}$ & $10 \mathrm{~F} 20 \mathrm{M}^{\mathrm{a}}$ & $10 \mathrm{~F} 20 \mathrm{M}$ \\
\hline Handedness & $29 R 2 L$ & $29 R 2 L$ & 29R $1 \mathrm{~L}$ & $28 R 2 L$ \\
\hline Age of onset (mean \pm SEM years) & $64.7 \pm 1.6$ & $\mathrm{~N} / \mathrm{A}$ & $68.6 \pm 1.3$ & $\mathrm{~N} / \mathrm{A}$ \\
\hline Age at investigation (mean \pm SEM years) & $68.5 \pm 1.7$ & $70.0 \pm 1.2$ & $72.3 \pm 1.7$ & $73.1 \pm 1.2$ \\
\hline Duration of symptoms (mean \pm SEM years) & $3.8 \pm 0.4$ & $\mathrm{~N} / \mathrm{A}$ & $3.7 \pm 0.4$ & $\mathrm{~N} / \mathrm{A}$ \\
\hline Years of education (mean \pm SEM years) & $12.4 \pm 0.6^{b c}$ & $14.5 \pm 0.5^{b}$ & $14.6 \pm 0.7^{c}$ & $15.17 \pm 0.6$ \\
\hline Body side most affected & $16 R 15 \mathrm{~L}$ & $\mathrm{~N} / \mathrm{A}$ & $\mathrm{N} / \mathrm{A}$ & $\mathrm{N} / \mathrm{A}$ \\
\hline
\end{tabular}

${ }^{\mathrm{a}}$ Fisher's Exact Test, $P=0.01 ;{ }^{b} \mathrm{t}[60]=-2.7, P=0.008 ;{ }^{c} \mathrm{t}[60]=2.4, P=0.02$. $\mathrm{F}$, female; $\mathrm{L}$, left; $\mathrm{M}$, male; N/A, not applicable; $\mathrm{R}$, right; SEM, standard error of the mean. 
practices. Sections from 50 paraffin blocks were examined. Stains and immunostains included Luxol Fast BlueHematoxylin and Eosin (LFB-H \& E), hyperphosporylated Tau, beta-amyloid, ubiquitin, alpha-synuclein, p62, glial fibrillary acidic protein (GFAP), CD2, Prussian blue and TDP-43.

\section{Results}

\section{Demographic data}

The demographic characteristics of the VHF-DLB, CBS and their respective control groups are shown in Table 1. Years of education was used as a covariate in the SPECT comparison of CBS versus controls because it was higher in the control group. Years of education and sex were used as covariates in all analyses relating to the comparison between the CBS and VHF-DLB groups given that they were different between the two patient groups and given that perfusion differences between men and women have been previously demonstrated using 99mTc-ECD SPECT [54].

\section{Clinical and pathological features}

Table 2 displays the clinical features of the DLB cohort at the time of entry into the study. Of the ten cases of possible

Table 2 Clinical characteristics of patients with VHF-DLB at the time of entry into the study

\begin{tabular}{|c|c|c|}
\hline Clinical characteristics & $\begin{array}{l}\text { Frequency }(\%) \text { at } \\
\text { investigation }(\mathrm{N}=30)\end{array}$ & $\begin{array}{l}\text { Frequency }(\%) \text { at } \\
\text { follow-up }(\mathrm{N}=30)\end{array}$ \\
\hline \multicolumn{3}{|l|}{ Core features } \\
\hline Parkinsonism & $26(86.7)$ & $30(100 \%)^{a}$ \\
\hline Rigidity & $24(80.0)$ & - \\
\hline Gait disturbance & $21(70.0)$ & - \\
\hline Bradykinesia & $20(66.7)$ & - \\
\hline Tremor & $17(56.7)$ & - \\
\hline Postural instability & $15(50.0)$ & - \\
\hline Hypomimia & $15(50.0)$ & - \\
\hline Fluctuating cognition & $18(60.0)$ & $18(60.0)$ \\
\hline Visual hallucinations & $0(0)$ & $0(0)$ \\
\hline \multicolumn{3}{|l|}{ Supportive features } \\
\hline $\begin{array}{l}\text { REM sleep behaviour } \\
\text { disorder }\end{array}$ & $7(23.3)$ & $7(23.3)$ \\
\hline Neuroleptic sensitivity & $3(10.0)$ & $3(10.0)^{b}$ \\
\hline \multicolumn{3}{|l|}{ Suggestive features } \\
\hline Depressive symptoms & $14(46.7)$ & $14(46.7)$ \\
\hline Systematised delusions & $7(23.3)$ & $7(23.3)$ \\
\hline Orthostatic hypotension & $5(16.7)$ & $5(16.7)$ \\
\hline Non-visual hallucinations & $5(16.7)$ & $5(16.7)$ \\
\hline Syncope & $1(3.3)$ & $1(3.3)$ \\
\hline
\end{tabular}

${ }^{a}$ All patients developed parkinsonism within one year of investigation; ${ }^{b}$ neuroleptic use avoided given DLB diagnosis. Only three patients were exposed to an antipsychotic and all had sensitivity. N, number; REM, rapid eye movement; VHF-DLB, visual hallucination-free dementia with Lewy bodies.
DLB, eight presented with spontaneous parkinsonism and dementia while two presented with fluctuating attention/ alertness and dementia. Of the 20 cases of probable DLB, ten presented with parkinsonism and marked fluctuations in attention and alertness; four exhibited parkinsonism, fluctuating attention/alertness and rapid eye movement (REM) sleep behaviour disorder; two exhibited parkinsonism and REM sleep behaviour disorder; two exhibited parkinsonism and neuroleptic sensitivity; one presented with fluctuating attention/alertness and REM sleep behavior disorder; and one exhibited fluctuating attention/alertness and REM sleep behavior disorder, all in the context of dementia. Of the core diagnostic features of DLB, parkinsonism was the most common at presentation $(87 \%, 26 / 30$ patients). Importantly, all DLB subjects went on to develop parkinsonism within one year of the initial investigation. As a result, two possible DLB cases met criteria for probable disease on longitudinal assessment bringing the total number of probable cases to 22. Of the parkinsonian features, rigidity and gait disturbance were the most prevalent. Fluctuating attention and alertness, also a core diagnostic feature was found in $60 \%(18 / 30)$ of the subjects. Visual hallucinations were not observed in this DLB cohort, which was the basis for their inclusion in this study. Nineteen of the 30 VHF-DLB patients were on cholinesterase inhibitors at the time of this study. However, none had exhibited visual hallucinations prior to initiation of therapy.

The clinical features of the CBS group are shown in Table 3 . Asymmetric apraxia $(90 \% ; 28 / 31)$ and rigidity (90\%; 28/31) were the most common features in this

Table 3 Clinical characteristics of CBS sample

\begin{tabular}{lcc}
\hline $\begin{array}{l}\text { Clinical } \\
\text { characteristics }\end{array}$ & $\begin{array}{l}\text { Frequency (\%) at time of } \\
\text { investigation (N =31) }\end{array}$ & $\begin{array}{l}\text { Frequency (\%) at } \\
\text { follow-up (N =31) }\end{array}$ \\
\hline $\begin{array}{l}\text { Extrapyramidal } \\
\text { features }\end{array}$ & $28(90.3 \%)$ & $31(100 \%)$ \\
$\begin{array}{l}\text { Rigidity (asymmetric) } \\
\text { Dystonia }\end{array}$ & $16(51.6 \%)$ & $18(58.1 \%)$ \\
$\begin{array}{l}\text { Levodopa trial with } \\
\text { poor response }\end{array}$ & $13(41.9 \%)$ & $13(41.9 \%)$ \\
$\begin{array}{l}\text { Tremor - postural/ } \\
\text { action }\end{array}$ & $8(25.8 \%)$ & $11(35.6 \%)$ \\
Cortical features & & \\
Apraxia & $28(90.3 \%)$ & $31(100 \%)$ \\
Cortical sensory loss & $19(61.3 \%)$ & $19(61.3 \%)$ \\
Alien-limb & $1(3.2 \%)$ & $3(9.7 \%)$ \\
phenomenon & $7(22.6 \%)$ & $10(32.3 \%)$ \\
Limb levitation & $9(29.0 \%)$ & $13(41.9 \%)$ \\
Myoclonus & $22(71.0 \%)$ & $22(71.0 \%)$ \\
Early dementia & $24(77.4 \%)$ & $24(77.4 \%)$ \\
\hline Language disturbance & & \\
\hline
\end{tabular}

Thirteen patients had a trial of levodopa and all responded poorly based on clinical assessment. Average time for emergence of additional symptoms or signs on follow-up was $1.0 \pm 0.3$ years. CBS, corticobasal syndrome; N, number. 
cohort initially, followed by language disturbance (77\%; $24 / 31)$ and early dementia (71\%; 2/31). Sixteen patients (51.6\%) presented with the right side of their body most affected while 15 (48.4\%) had a left-sided presentation. We retrospectively applied the new diagnostic criteria for CBS [55]. Sixteen of our CBS cases met the new criteria for probable CBS while 15 met possible criteria.

Figure 2 demonstrates the frequency of the core signs and symptoms of each of the clinical diagnostic categories across both the VHF-DLB and CBS groups. As expected based on the design of this study, there were several differences in the frequency of clinical signs and symptoms between the VHF-DLB and CBS groups. Specifically, asymmetry of the apraxia and/or motor signs, and presence of apraxia, dystonia, myoclonus and cortical sensory loss were more frequent in the CBS group. There were no differences between the presence of parkinsonism or true alien limb phenomenon noted although the latter was an uncommon feature in our CBS group. The VHF-DLB group had a higher occurrence of early cognitive impairment, fluctuations in attention and/or alertness and the presence of REM behavioral disorder.

Subsequent pathology was obtained in three subjects in the VHF-DLB group, all of whom had pathological confirmation of Lewy body disease with all demonstrating concomitant Alzheimer's pathology and small vessel arteriosclerosis. Nine subjects in the CBS group came to autopsy with pathological diagnoses of pure CBD in five, mixed disease - dementia with agyrophilic grains + CBD + cerebral amyloid angiopathy in one, PSP in two, and FTLD-U/TDP43 proteinopathy due to mutation in the progranulin gene $(G R N)$ in one [56]. None of the CBS cases had Lewy bodies, Lewy neurites or other alphasynuclein positive inclusions.

\section{Neuropsychological data}

The complete neuropsychological, neuropsychiatric and functional profiles of both patient groups are shown in Table 4. The CBS and VHF-DLB groups did not differ on the MMSE or DRS. After controlling for effects of sex and years of education, the VHF-DLB group demonstrated more marked impairment compared to the CBS group on the CVLT-long delay free recall (mean \pm SEM $=2.4 \pm 0.5$ versus $6.6 \pm 0.6$, respectively; $\mathrm{F}(1,42)=23.1, P<0.001)$ and CVLT-long delay cued recall (mean \pm SEM $=3.9 \pm 0.5$ versus $7.4 \pm 0.6$, respectively; $\mathrm{F}(1,42)=14.0, P=0.001)$ as well as the WMS-R delayed visual reproduction (mean \pm $\mathrm{SEM}=4.2 \pm 1.2$ versus $10.5 \pm 2.3$, respectively; $\mathrm{F}(1,36)=9.7$, $P=0.004$ ). Because of the observed CVLT differences, we performed secondary analyses to determine if the impairments seen in the VHF-DLB group on recall were due to encoding or retrieval deficits. Both groups demonstrated a similar benefit from cueing on the CVLT (data not shown). However, using the sum of the total number of words retained after each learning trial (one through five), the VHF-DLB group was found to perform more poorly on encoding than the CBS group (VHF-DLB: $21.6 \pm 2.4$ versus CBS: $31.3 \pm 2.0 ; \mathrm{F}(1,42)=8.5, P=0.006)$.

\section{SPM and ROI SPECT analysis}

Figure 3 shows the voxel clusters for which a significant reduction in perfusion in the CBS and VHF-DLB groups

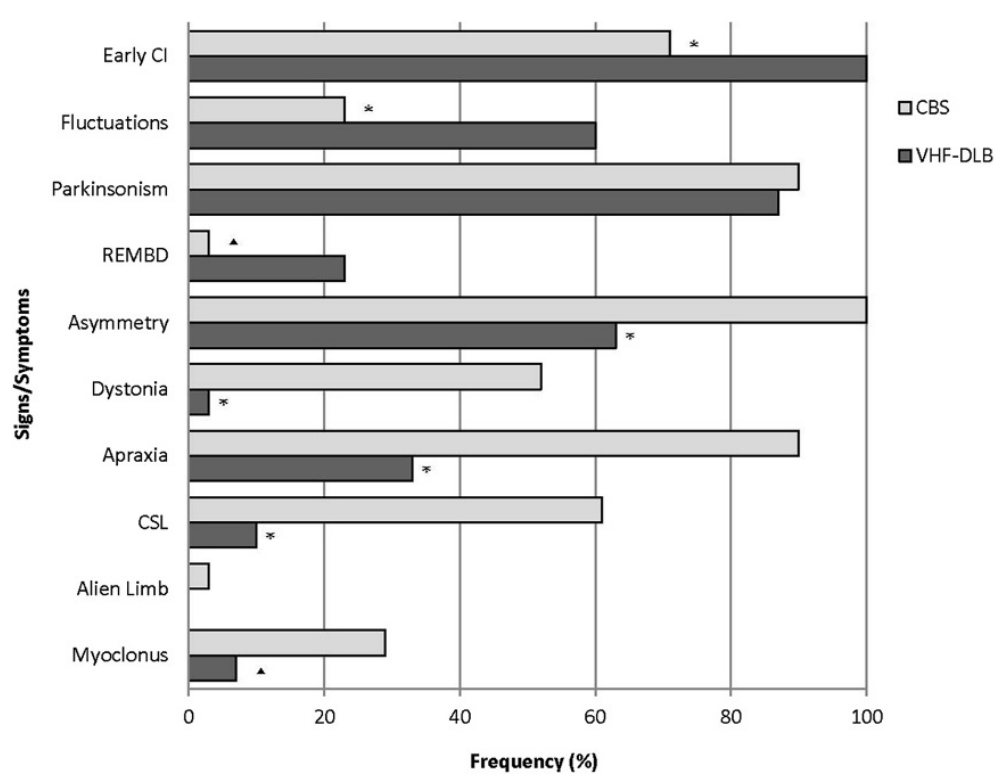

Figure 2 Bar graph comparing frequency of core signs and symptoms in the CBS versus VHF-DLB groups. ${ }^{*} P<0.005 ; \mathbf{\Delta} P<0.05$. CBS, corticobasal syndrome; VHF-DLB, visual hallucination-free dementia with Lewy bodies. 
Table 4 Mean $( \pm$ SEM) scores on neuropsychological, neuropsychiatric and functional measures in the CBS and VHF-DLB groups

\begin{tabular}{|c|c|c|}
\hline Psychometric measures & CBS (number) & VHF-DLB (number \\
\hline \multicolumn{3}{|l|}{ General cognition } \\
\hline MMSE/30 (number =59) & $21.7 \pm 1.2(31)$ & $22.1 \pm 1.1(28)$ \\
\hline $\begin{array}{l}\text { Clock Drawing Test/10 } \\
\text { (number =26) }\end{array}$ & $6.9 \pm 0.8(9)$ & $7.7 \pm 0.6(17)$ \\
\hline NART/127.8 (number =38) & $107.5 \pm 1.9(19)$ & $108.4 \pm 2.1(19)$ \\
\hline $\begin{array}{l}\text { Raven's Progressive } \\
\text { Matrices (number =40) }\end{array}$ & $21.9 \pm 1.6(22)$ & $21.2 \pm 1.3(18)$ \\
\hline DRS/144 (number =53) & $113.5 \pm 4.1(26)$ & $114.6 \pm 3.7(27)$ \\
\hline \multicolumn{3}{|l|}{ Memory } \\
\hline $\begin{array}{l}\text { CVLT Long Delay Free } \\
\text { Recall/16 (number }=46)^{a}\end{array}$ & $6.6 \pm 0.6(21)$ & $2.4 \pm 0.5(25)$ \\
\hline $\begin{array}{l}\text { CVLT Long Delay Cued } \\
\text { Recall/16 (number }=46)^{a}\end{array}$ & $7.4 \pm 0.6(21)$ & $3.9 \pm 0.5(25)$ \\
\hline $\begin{array}{l}\text { Delayed Visual Reproduction } \\
/ 41 \text { (number }=40^{b}\end{array}$ & $10.5 \pm 2.3(19)$ & $4.2 \pm 1.2(21)$ \\
\hline \multicolumn{3}{|l|}{ Language } \\
\hline WAB total/100 (number =38) & $85.7 \pm 2.5(23)$ & $86.5 \pm 2.2(15)$ \\
\hline $\begin{array}{l}\text { Boston Naming/30 } \\
\text { (number }=47 \text { ) }\end{array}$ & $24.0 \pm 1.0(22)$ & $22.5 \pm 1.1(25)$ \\
\hline $\begin{array}{l}\text { Semantic Fluency/20 } \\
\text { (number }=53 \text { ) }\end{array}$ & $9.8 \pm 1.2(26)$ & $10.3 \pm 1.0(27)$ \\
\hline \multicolumn{3}{|l|}{ Praxis } \\
\hline WAB praxis/60 ( $n=48)$ & $53.2 \pm 1.6(27)$ & $55.6 \pm 0.6(21)$ \\
\hline \multicolumn{3}{|l|}{$\begin{array}{l}\text { Attention and working } \\
\text { memory }\end{array}$} \\
\hline $\begin{array}{l}\text { Digit span - forward/12 } \\
\text { (number =50) }\end{array}$ & $7.0 \pm 0.6(23)$ & $6.8 \pm 0.5(27)$ \\
\hline $\begin{array}{l}\text { Digit span - backward/12 } \\
\text { (number =50) }\end{array}$ & $4.6 \pm 0.6(23)$ & $4.3 \pm 0.5(27)$ \\
\hline \multicolumn{3}{|l|}{ Visuospatial abilities } \\
\hline $\begin{array}{l}\text { Rey Osterieth Complex } \\
\text { Figure/36 (number }=45 \text { ) }\end{array}$ & $17.0 \pm 3.0(20)$ & $18.5 \pm 2.3(25)$ \\
\hline $\begin{array}{l}\text { Benton Line Orientation } \\
\text { /30 (number }=44)\end{array}$ & $13.2 \pm 2.4(21)$ & $13.4 \pm 2.3(23)$ \\
\hline \multicolumn{3}{|l|}{ Executive functions } \\
\hline $\begin{array}{l}\text { Phonemic (FAS) fluency } \\
\text { (number }=47 \text { ) }\end{array}$ & $19.1 \pm 2.7(21)$ & $22.1 \pm 3.2(26)$ \\
\hline $\begin{array}{l}\text { Trail Making Test A (time in } \\
\text { seconds) (number }=42 \text { ) }\end{array}$ & $108.7 \pm 14.7(19)$ & $101.4 \pm 11.5(23)$ \\
\hline $\begin{array}{l}\text { Trail Making Test B (time in } \\
\text { seconds) (number }=31 \text { ) }\end{array}$ & $214.5 \pm 39.7(13)$ & $193.6 \pm 20.9(18)$ \\
\hline $\begin{array}{l}\text { WCST categories } / 6 \\
\text { (number }=44 \text { ) }\end{array}$ & (22) & $(22)$ \\
\hline Categories 0 to 1: Counts (\%) & $11(50 \%)$ & 17 (77\%) \\
\hline Categories 2 to 4 : Counts (\%) & $11(50 \%)$ & $5(23 \%)$ \\
\hline $\begin{array}{l}\text { WCST perseverative errors } \\
\text { (number }=44 \text { ) }\end{array}$ & $11.7 \pm 2.9(22)$ & $19.8 \pm 3.4(22)$ \\
\hline
\end{tabular}

Table 4 Mean $( \pm$ SEM) scores on neuropsychological, neuropsychiatric and functional measures in the CBS and VHF-DLB groups (Continued)

Neuropsychiatric

features

Cornell Depression

(number =54)

Neuropsychiatric

Inventory/144

(number $=55$ )

\section{Functional measures}

DAD (\%) (number $=57)$

$68.8 \pm 5.7(30)$

$78.9 \pm 4.1(27)$

${ }^{\mathrm{a}} P<0.005 ;{ }^{\mathrm{b}} P<0.05$. The number of patients tested is listed next to individual measures. Missing data are secondary to the inability of the patient to complete the test. CBS, corticobasal syndrome; CVLT, California Verbal Learning Test; DAD, Disability Assessment Scale for Dementia; DRS, Mattis Dementia Rating Scale; FAS, F-, A-, and S-phonemic fluency; MMSE, Folstein's Mini-Mental State Exam; NART, National Adult Reading Test; SEM, standard error of the mean; VHF-DLB, visual hallucination-free dementia with Lewy bodies; WAB, Western Aphasia Battery; WCST, Wisconsin Card Sort Test.

were found relative to normal controls. The SPM analysis revealed significant reductions in perfusion after correcting the FWE (most conservative) in the right superior frontal gyrus and left middle frontal gyrus in the CBS group relative to controls (Table 5). Analysis after correcting the FDR (less conservative) revealed bilateral hypoperfusion in the medial and dorsolateral frontal area, and parietal regions in the CBS groups relative to controls (Table 5). The VHF-DLB group demonstrated significant reductions in the left and right middle temporal gyri, right superior parietal lobule, left precuneus, left superior temporal gyrus, left inferior parietal lobule and left middle occipital gyrus relative to controls (FWE-corrected) (See Table 6). Less conservative correction methods using the FDR revealed the same regions of reduced perfusion as demonstrated by FWE-correction methods in addition to symmetrical, bilateral hypoperfusion in frontal and temporal regions and in the left caudate in VHF-DLB compared to controls (Table 6). There were no areas of increased perfusion seen in the controls relative to both patient groups.

We then examined for perfusion differences between the VHF-DLB and CBS groups directly using the pre-specified hypothesis that areas differentiating the two patient groups will reside within non-overlapping regions of reduced perfusion identified in their respective case versus control comparisons (Figure 1). Using a MANCOVA model controlling for effects of sex and years of education with the independent variable being patient group and the dependent variables being perfusion ratios in ROIs, the left occipital pole was found to be the only ROI showing reduced perfusion in the VHF-DLB patients compared to the CBS group $\left(F(19,39)=2.66, P=0.005\right.$; Wilk's $\Lambda=0.44$, partial $\eta^{2}=$ $0.56)$. The corrected mean perfusion ratio \pm SEM for the VHF-DLB group was $0.80 \pm 0.02$ versus $0.88 \pm 0.02$ for the 


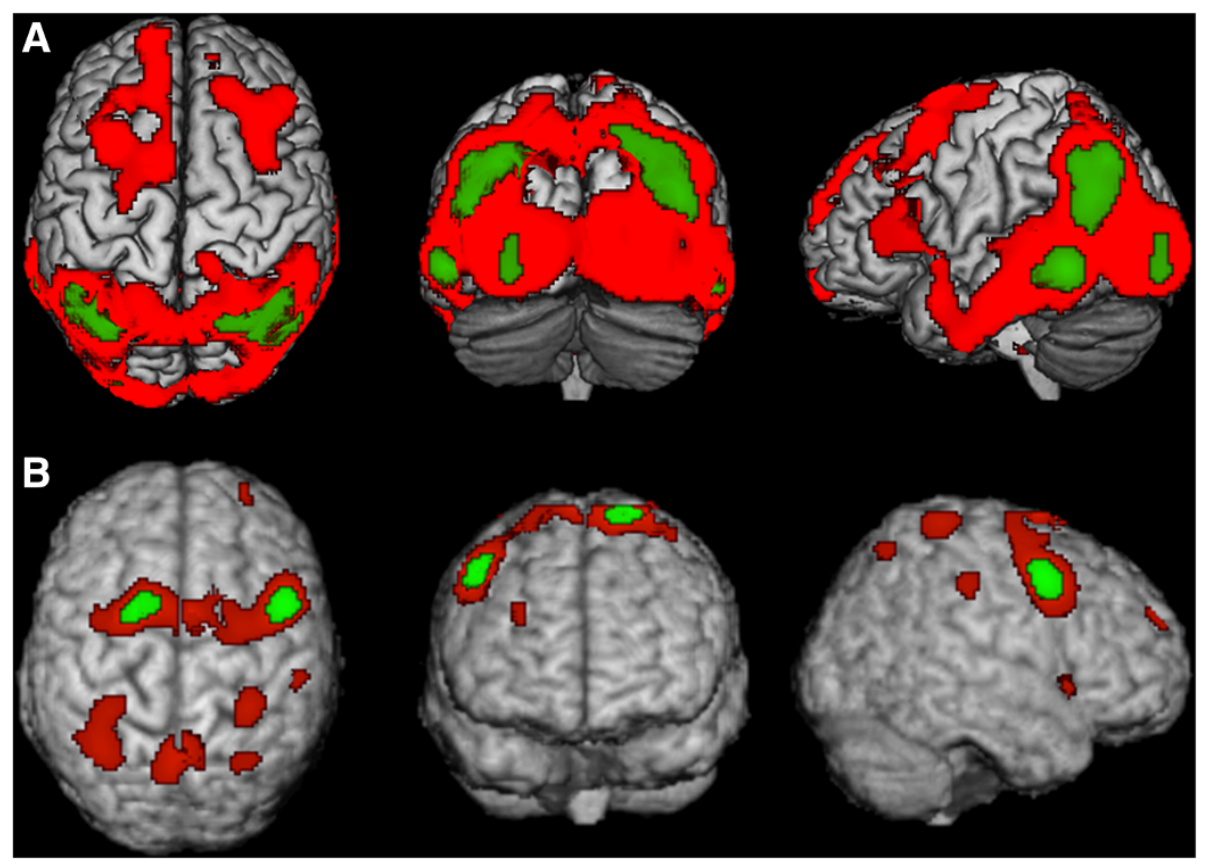

Figure 3 Statistical Parametric Map (SPM) depicting regions of decreased perfusion in A) VHF-DLB and B) CBS relative to controls. Red areas are corrected for multiple testing using the False Discovery Rate, while green areas are corrected using the more conservative Family Wise Error method. Views are shown in standard anatomical orientation.

CBS group $\left(\mathrm{F}(1,57)=7.4, P=0.009, \mathrm{R}^{2}=0.13\right.$ (post-hoc univariate analysis)). No other ROIs showed differential perfusion between the patient groups. This finding was subsequently confirmed using SPM. Specifically, after controlling for the effects of years of education and sex in SPM, the left cuneus (Brodmann Area 18; Talairach coordinates $\mathrm{x}=-14, \mathrm{y}=-96$, and $\mathrm{z}=4$; number of voxels in the cluster $=159$ ) was found to show reduced perfusion in the VHF-DLB group compared to the CBS group (SPM t-score $=3.9, P<0.001$ [uncorrected]).

\section{MRI ROI cortical volumetric and thickness analysis}

Several bilateral cortical ROI volume measures and one cortical ROI thickness measure within frontal, temporal and parietal regions were found to be reduced in the CBS group compared to the VHF-DLB group in the independent samples t-test analysis. These ROI volumetric and thickness measures were incorporated into a MANCOVA analysis and the overall model that controlled for sex, years of education, and total intracranial volume did not show any statistically significant differences between the VHF-DLB and CBS groups with respect to cortical ROI volume and thickness measures.

\section{Logistic regression predicting group membership}

A logistic regression was performed to determine the effects of CVLT-long delay free recall score and perfusion within the left occipital pole on predicting patient group membership (that is, VHF-DLB versus CBS). So as to not violate the assumption of independence of observations required for logistic regression, the CVLT-long delay cued recall and WMS-R delayed visual reproduction were not included in this model because they were strongly correlated with the CVLT-long delay free recall (data not shown). The overall logistic regression model was statistically significant $\left(X^{2}[2]=23.7, P<0.0005\right)$. The model correctly classified $80.4 \%$ of cases and accounted for $53.9 \%$ (Nagelkerke $R^{2}$ ) of the variance in patient group membership. CVLT-long delay free recall was the only independent variable that correctly predicted group membership (Wald test $[1]=10.7, P=0.001$ ). Specifically, worse performance on this memory test was associated with an increased likelihood of belonging to the VHF-DLB group.

\section{Discussion}

This study demonstrated that neuropsychological measures assessing both verbal and visual episodic memory combined with perfusion in the left occipital region may be useful in distinguishing between VHF-DLB and CBS. Specifically, we have found that the VHF-DLB group performed worse on the CVLT long delay free and cued recall as well as on the WMS-R delayed visual reproduction task and showed decreased perfusion in the left occipital pole ROI compared to CBS patients. However, in a logistic regression analysis, the CVLT long delay free recall scores had better predictive value than left occipital pole 
Table 5 Areas of relative hypoperfusion on SPECT when CBS compared to their respective control groups

\begin{tabular}{|c|c|c|c|c|c|}
\hline \multirow{2}{*}{$\begin{array}{l}\text { Anatomical locus (Brodmann } \\
\text { area) }\end{array}$} & \multicolumn{3}{|c|}{ Talairach coordinates } & \multirow[t]{2}{*}{ Number of voxels } & \multirow[t]{2}{*}{ SPM t-score ( $P$-value $)$} \\
\hline & $\mathbf{x}$ & y & z & & \\
\hline \multicolumn{6}{|l|}{ CBS versus controls (FWE-corr) } \\
\hline Right middle frontal gyrus (6) & 50 & 8 & 42 & 236 & $5.4(P=0.003)$ \\
\hline Left superior frontal gyrus (6) & -18 & 9 & 70 & 99 & $5.4(P=0.005)$ \\
\hline \multicolumn{6}{|l|}{ CBS versus controls (FDR-corr) } \\
\hline Right middle frontal gyrus (6) & 50 & 8 & 42 & 1791 & $5.4(P=0.005)$ \\
\hline Right superior frontal gyrus (6) & 6 & 7 & 70 & & $4.7(P=0.007)$ \\
\hline Right sub-gyrus (6) & 30 & -1 & 55 & & $4.0(P=0.014)$ \\
\hline Left superior frontal gyrus (6) & -18 & 9 & 70 & 850 & $5.4(P=0.005)$ \\
\hline Left superior frontal gyrus (6) & 0 & -2 & 68 & & $3.5(P=0.020)$ \\
\hline Left middle frontal gyrus (6) & -26 & -1 & 50 & & $3.6(P=0.019)$ \\
\hline Left precentral gyrus (9) & -34 & 9 & 31 & 203 & $4.4(P=0.009)$ \\
\hline Left precuneus (7) & -2 & -57 & 62 & 655 & $4.4(P=0.009)$ \\
\hline Right precuneus (7) & 4 & -53 & 65 & & $4.4(P=0.010)$ \\
\hline Left postcentral gyrus (7) & -4 & -51 & 67 & & $3.7(P=0.017)$ \\
\hline Left superior parietal lobule (7) & -34 & -53 & 60 & 834 & $4.1(P=0.013)$ \\
\hline Left superior parietal lobule (7) & -32 & -46 & 47 & & $3.8(P=0.017)$ \\
\hline Left postcentral gyrus (2) & -30 & -37 & 70 & & $4.0(P=0.015)$ \\
\hline Right postcentral gyrus (2) & 34 & -35 & 68 & 213 & $4.1(P=0.013)$ \\
\hline Right postcentral gyrus (2) & 48 & -27 & 40 & 163 & $3.9(P=0.015)$ \\
\hline Right inferior frontal gyrus (47) & 44 & 17 & -3 & 96 & $3.8(P=0.016)$ \\
\hline Right superior frontal gyrus (10) & 32 & 57 & 23 & 31 & $3.8(P=0.017)$ \\
\hline Right superior parietal lobule (7) & 32 & -59 & 58 & 67 & $3.7(P=0.017)$ \\
\hline
\end{tabular}

CBS, corticobasal syndrome; FDR-corr, corrected for False Discovery Rate; FWE-corr, corrected for Family-Wise Error; SPECT, single-photon emission computed tomography; SPM, Statistical Parametric Mapping.

perfusion in terms of determining group membership. The CBS and VHF-DLB groups did not differ on MMSE or DRS, suggesting that they were well-matched for dementia severity, which was in the mild stages in both groups. Both patient groups also had a similar duration of disease at the time of investigation, therefore, making it unlikely to be a confounding factor.

CBS and DLB groups often exhibit primarily executive dysfunction greater than memory impairment, exemplified by disproportionate deficits when performing the WCST, Stroop test, TMT, and Delis-Kaplan Executive Function System [57-60]. Visuospatial dysfunction has also been shown to be disproportionately severe in DLB patients, when assessed using standardised measures such as the Benton Judgment of Line Orientation (BJLO) or the Rey-Ostereith Complex Figure Copy Paradigm (ROCF-CP) [61]. Such deficits have been attributed to problems with perceptual processing and apraxia in DLB patients [62,63]. When compared to PSP and Multiple System Atrophy (MSA), CBS has been shown to have the most consistent and severe impairment of visuospatial function on the BJLO and the Visual Object and Space
Perception Battery (VOSP) [64,65]. Indeed, tests assessing general cognition, attention and working memory, executive functions, language, praxis and visuospatial abilities did not distinguish between the VHF-DLB and CBS groups included in this study indicating substantial overlap in their overall clinical neuropsychological profiles.

The CVLT is a standardized and validated test of verbal episodic memory function and is a widely used measure in the dementia literature [66]. Our results suggest that although CBS and VHF-DLB patients both benefit similarly from cueing, indicating that frontal-subcortical dysfunction contributes to their memory deficits, the VHF-DLB group recalled fewer words overall compared to the CBS group. This may be due to more severe encoding versus retrieval problems in the VHF-DLB group. The sum of the total number of words retained after learning trials, one through five, was significantly lower in the VHF-DLB group suggesting that this group had more troubles with encoding than the CBS group. This may be due to concomitant AD pathology in the VHF-DLB group, which is consistent with prior studies showing significant pathological overlap between DLB and AD [1] as well as the 
Table 6 Areas of relative hypoperfusion on SPECT when VHF-DLB is compared to their respective control group

\begin{tabular}{|c|c|c|c|c|c|}
\hline \multirow[t]{2}{*}{ Anatomical locus (Brodmann area) } & \multicolumn{3}{|c|}{ Talairach coordinates } & \multirow[t]{2}{*}{ Number of voxels } & \multirow[t]{2}{*}{ SPM t-score ( $P$-value $)$} \\
\hline & $\bar{x}$ & $\mathbf{y}$ & $\mathbf{z}$ & & \\
\hline \multicolumn{6}{|l|}{ VHF-DLB versus controls (FWE-corr) } \\
\hline Left middle temporal gyrus (21) & -57 & -49 & -3 & 413 & $6.2(P=0.000)$ \\
\hline Right middle temporal gyrus (39) & 44 & -63 & 31 & 1292 & $5.9(P=0.001)$ \\
\hline Right superior parietal lobule (7) & 30 & -64 & 46 & & $5.6(P=0.003)$ \\
\hline Left precuneus (19) & -34 & -64 & 42 & 1195 & $5.9(P=0.001)$ \\
\hline Left superior temporal gyrus (39) & -48 & -57 & 27 & & $5.7(P=0.002)$ \\
\hline Left inferior parietal lobule (40) & -46 & -56 & 39 & & $5.5(P=0.004)$ \\
\hline Right middle temporal gyrus (21) & 61 & -35 & -10 & 211 & $5.4(P=0.005)$ \\
\hline Left middle occipital gyrus & -28 & -89 & -2 & 100 & $5.1(P=0.013)$ \\
\hline \multicolumn{6}{|l|}{ VHF-DLB versus controls (FDR-corr) } \\
\hline Left middle frontal gyrus (21) & -57 & -49 & -3 & 33550 & $6.2(P=0.000)$ \\
\hline Left precuneus (19) & -34 & -64 & 42 & & $5.9(P=0.000)$ \\
\hline Right middle temporal gyrus (39) & 44 & -63 & 31 & & $5.9(P=0.000)$ \\
\hline Right middle frontal gyrus (8) & 36 & 16 & 45 & 1743 & $3.9(P=0.002)$ \\
\hline Right middle frontal gyrus (9) & 36 & 27 & 37 & & $3.9(P=0.002)$ \\
\hline Right superior frontal gyrus (8) & 20 & 39 & 39 & & $3.7(P=0.003)$ \\
\hline Left medial frontal gyrus (11) & -4 & 61 & -15 & 144 & $3.7(P=0.003)$ \\
\hline Right inferior frontal gyrus (47) & 50 & 27 & -3 & 344 & $3.6(P=0.004)$ \\
\hline Left sub-lobar caudate & -14 & 10 & 5 & 41 & $3.4(P=0.006)$ \\
\hline Right superior frontal gyrus (9) & 14 & 52 & 25 & 23 & $3.2(P=0.008)$ \\
\hline
\end{tabular}

FDR-corr ,corrected for False Discovery Rate; FWE-corr, corrected for Family-Wise Error; SPECT, single-photon emission computed tomography; SPM, Statistical Parametric Mapping; VHF-DLB, visual hallucination-free dementia with Lewy bodies.

finding that three of our VHF-DLB cases that came to autopsy all demonstrated concomitant DLB, AD as well as arteriosclerosis. While the inclusion of possible VHF-DLB cases increases the likelihood that these patients may have AD pathology and not DLB, the fact that all of our VHFDLB cases had parkinsonism makes pure AD pathology very unlikely in this patient group.

The SPECT data showed typical perfusion profiles of CBS [67-70] and DLB [46], as demonstrated in prior studies. This strongly supports that our patient groups were similar to other published case series and improves on diagnostic accuracy. Areas of relative hypoperfusion have been found to involve frontal and parietal regions in both DLB and CBS [46,69,71]. While bilateral perfusion deficits are characteristic of DLB [72], CBS patients tend to show asymmetrical perfusion syndromes in most $[71,73]$, but not all, studies [69]. These prior studies demonstrate overlap in the hypoperfused brain regions found on SPECT in both DLB and CBS.

Reduced perfusion in the left occipital pole ROI was observed in the VHF-DLB group compared to the CBS group, while there were no brain ROIs with significantly reduced perfusion observed in the CBS relative to the VHF-DLB group. Occipital hypoperfusion most pronounced at the parieto-occipital junction on SPECT is a well-known feature of DLB [46,72] and is one of the supportive features in the consensus diagnostic criteria [9]. Occipital lobe dysfunction in DLB was first demonstrated using fluoro-deoxyglucose positron emission tomography (FDG-PET) [74,75]. It was later shown that occipital lobe abnormalities could be used to differentiate DLB from $\mathrm{AD}$, with a sensitivity and specificity ranging as high as 92\% for both [76-78]. Subsequently, occipital lobe dysfunction was confirmed using SPECT tracers including I-labelled isopropyl-iodoamphetamine SPECT [79] and 99 m Tc-HMPAO SPECT [80]. Pasquier et al. [81] demonstrated decreased bilateral occipital lobe perfusion in DLB as compared to AD using $99 \mathrm{~m}$ Tc-ECD SPECT. Bilateral occipital lobe hypoperfusion in combination with maintained perfusion within the left internal temporal region has been shown to favour a diagnosis of DLB over AD with $65 \%$ sensitivity and $71 \%$ specificity $[81,82]$.

The left occipital pole ROI in our SPECT template contained 712 voxels, mainly in BA 18 and part of BA 17, comprising secondary visual association and the primary visual cortices, respectively. This ROI includes the following neuroanatomical structures that function together to interpret the visual world: cuneus, lingual gyrus and lateral occipital gyrus. A more conservative SPM analysis confirmed that the left cuneus showed significant reductions 
in perfusion in the VHF-DLB group compared to the CBS patients. The cuneus is involved in primary visual processing, particularly in integrating ocular position signals to process stimuli position in space [83]. It has also been shown to have a variety of roles within the cognitive domain, including response inhibition [84], working memory [85] and behavioural engagement in cognitive control [86]. The lingual gyrus is involved in visual memory [87], encoding of complex images [88] and identification/recognition of letters and words $[89,90]$. A more recent resting state functional MRI study also identified a role of the bilateral lingual gyri in object colour knowledge [91,92]. The lateral occipital complex may play an important role in the recognition and perception of objects [93]. Many of these processes are selectively impaired in individuals suffering from DLB.

Our study had both strengths and limitations that warrant discussion. A main strength was our relatively large sample size given the rarity of both diagnostic groups included. An important limitation is the lack of pathological confirmation in the majority of our cases. However, a portion of each group was confirmed with the predicted pathology. All three of the VHF-DLB cases were confirmed to have DLB, and six of the nine CBS subjects autopsied had pathologic verification of $C B D$, a ratio consistent with previous studies [5]. The remaining CBS cases had pathology recognized to cause a CBS and none had additional Lewy body or other alpha-synuclein-related pathology. To overcome the lack of pathological confirmation in our sample, we chose as a first step in this line of investigation to include individuals meeting consensus diagnostic criteria for CBS and VHF-DLB. We acknowledge that this may reduce the chances that our findings are generalisable to earlier clinical stages of VHF-DLB and CBS. Therefore, we will plan to validate our findings in an independent cohort of pathologically confirmed cases that is being ascertained with both diagnoses and that have been followed from early stages using CVLT and brain SPECT when they are particularly hard to distinguish from each other. Thus, these results represent the first phase of an ongoing project. Importantly though, we demonstrate that many of the VHF-DLB patients have overlapping clinical features with the CBS group and vice versa. An additional limitation is the reduced statistical power for the neuroimaging analyses, which is likely the reason why the perfusion differences between the VHF-DLB and CBS groups localised only to the left occipital region and not to the corresponding contralateral side and why the MRI volumetric and thickness measures did not show any differences between the patient groups. This is especially the case for the analysis of MRI data as there were only 21 useable MRIs in the CBS group and 23 in the VHF-DLB group. Despite this limitation, our results suggest that perfusion measures may be more sensitive than atrophy measures in syndromes that have some degree of clinical overlap. This is supported by prior research of focal cortical atrophy syndromes, such as FTLD, whereby perfusion reductions on SPECT are more extensive than atrophy detected on MRI in the early stages of disease and in longitudinal follow-up, indicating increased sensitivity of this modality as a potential biomarker [94-96].

\section{Conclusions}

In spite of the limited pathology available, the benefit of our study is that it provides neuropsychological and neuroimaging features useful for differentiating VHF-DLB and CBS in the antemortem period. Indeed, the diagnostic challenges faced by clinicians are in the antemortem period, when only syndromic presentations, and a lack of any pathological verification, are available to inform their diagnostic considerations. Our segregation of VHFDLB and CBS groups, based on expert consensus and strongly supported by SPECT perfusion profiles, represents the same information that clinicians will need to rely on to inform treatment decisions, without the guidance of pathology. Therefore, our study provides clinicians with information they can use in difficult cases to help support diagnostic stratification and treatment plans for these two overlapping clinical entities.

\section{Abbreviations}

ANCOVA: analysis of covariance; BA: Brodmann area; BJLO: Benton Judgment of Line Orientation; BNT: Boston Naming Test; CBD: corticobasal degeneration; CBS: corticobasal syndrome; CSDD: Cornell Scale for Depression in Dementia; CSF: cerebrospinal fluid; CVLT: California verbal learning test; DAD: Disability Assessment for Dementia; DLB: dementia with Lewy bodies; DRS: Dementia Rating Scale; FDG-PET: fluoro-deoxyglucose positron emission tomography; FDR: false discovery rate; FMRIB: functional magnetic resonance imaging of the brain; FOV: field of view; FTLD: frontotemporal lobar degeneration; FWE:

family-wise error; FWHM: full width at half maximum; GFAP: glial fibrillary acidic protein; LFB-H \& E: luxol fast blue-haematoxylin and eosin;

MANCOVA: multivariate analysis of variance; MMSE: Mini-Mental State Exam; MNI: Montreal Neurologic Institute; MRI: magnetic resonance imaging; MSA: multiple system atrophy; NART-R: National Adult Reading Test-Revised; NEX: number of excitations; NPI: Neuropsychologic Inventory; PD: proton density; PSP: progressive supranuclear palsy; rCBF: regional cerebral blood flow; REM: rapid eye movement; ROCF-CP: Rey-Ostereith Complex Figure Copy Paradigm; ROI: region of interest; SPECT: single-photon emission computed tomography; SPGR: spoiled gradient; SPM: statistical parametric mapping; SPSS: Statistical Package for the Social Sciences; TDP-43: TAR DNA binding protein 43; TE: echo time; TMT-A and -B: Trail Making Test A and B; TR: repetition time; VHF-DLB: visual hallucination-free dementia with Lewy bodies; VOSP: Visual Object and Space Perception Battery; WAB: Western Aphasia Battery; WCST: Wisconsin Card Sort Test; WMS-R: Wechsler Memory Scale-Revised.

\section{Competing interests}

The authors declare that they have no competing interests.

\section{Authors' contributions}

MRM was responsible for data extraction and analysis, and drafting the introduction, methods and results section of the manuscript. SM was responsible for drafting the discussion section of the manuscript. PLF assisted with the statistical parametric mapping analysis. KS was involved in collection and assembly of the neuropsychological data. KM was responsible for clinical data extraction. AM, KH, JZ and CS were involved in the processing and analysis of the MRI data. CBC and LE were involved in the 
SPECT acquisition protocol and revision of the manuscript. PS was involved in interpretation of the neuropsychological data. BJM provided a critical revision to the manuscript with respect to the imaging analytical methods. JMB conducted the neuropathological analysis and provided the pathological diagnoses. AEL and SEB were involved in clinical data acquisition and ensuring appropriate clinical diagnostic criteria were met, and also critically revised the manuscript. SEB was also involved in overseeing the conduct of the Sunnybrook Dementia Study. MM was involved in the conception and design of the study, data acquisition and analysis, interpretation of data, ensuring appropriate clinical diagnostic criteria were met and drafting of the manuscript. All authors have read and approved of the final version of the manuscript.

\section{Acknowledgements}

The authors would like to thank Ms. Michelle Messner for her help in putting together the references, Mr. Julian Li for creating Figure 1, and Courtney Berezuk for her help in processing the MRI data. This grant was supported by a Parkinson Society Canada New Investigator Award to MM and a CIHR operating grant (MT-13129) to SEB. MM receives research support from the Canadian Institutes of Health Research (CIHR), Ministry of Economic Development and Innovation of Ontario, Consortium of Canadian Centres for Clinical Cognitive Research (C5R) and Teva Pharmaceuticals and salary support from the Department of Medicine (Sunnybrook HSC and University of Toronto), and the Sunnybrook Foundation. SEB receives research support from CIHR, the Heart and Stroke Foundation of Canada, the Department of Medicine (Sunnybrook HSC and University of Toronto), and the Brill Chair in Neurology, University of Toronto.

\section{Author details}

${ }^{1}$ L.C. Campbell Cognitive Neurology Clinic, Sunnybrook Health Sciences Centre, Room A4 42, 2075 Bayview Avenue, Toronto, ON M4N 3M5, Canada. ${ }^{2}$ Department of Medical Biophysics, Sunnybrook Health Sciences Centre, University of Toronto, Room A4 42, 2075 Bayview Avenue, Toronto, ON M4N 3M5, Canada. ${ }^{3}$ Department of Nuclear Medicine, Sunnybrook Health Sciences Centre, University of Toronto, Room A4 42, 2075 Bayview Avenue, Toronto, ON M4N 3M5, Canada. ${ }^{4}$ Neuropsychology Clinic, Sunnybrook Health Sciences Centre, Room A4 42, 2075 Bayview Avenue, Toronto, ON M4N 3M5, Canada. ${ }^{5}$ Department of Pathology, Sunnybrook Health Sciences Centre, University of Toronto, Room A4 42, 2075 Bayview Avenue, Toronto, ON M4N 3M5, Canada. ${ }^{6}$ Morton and Gloria Shulman Movement Disorders Clinic and the Edmond J. Safra Program in Parkinson's Disease, Toronto Western Hospital, University Health Network, Toronto, Canada. ${ }^{7}$ Department of Medicine (Neurology), Brain Sciences Research Program, Sunnybrook Health Sciences, Centre University of Toronto, Room A4 42, 2075 Bayview Avenue, Toronto, ON M4N 3M5, Canada. ${ }^{8}$ Cognition \& Movement Disorders Clinic, Sunnybrook Health Sciences Centre, Room A4 42, 2075 Bayview Avenue, Toronto, ON M4N 3M5, Canada. ${ }^{9}$ Neurogenetics Section, Centre for Addiction and Mental Health, University of Toronto, Room A4 42, 2075 Bayview Avenue, Toronto, ON M4N 3M5, Canada.

Received: 10 October 2013 Accepted: 8 October 2014

Published online: 05 December 2014

\section{References}

1. Merdes AR, Hansen LA, Jeste DV, Galasko D, Hofstetter CR, Ho GJ, Thai LJ, Corey-Bloom J: Influence of Alzheimer pathology on clinical diagnostic accuracy in dementia with Lewy bodies. Neurology 2003, 60:1586-1590.

2. Kertesz A, McMonagle P, Blair M, Davidson W, Munoz DG: The evolution and pathology of frontotemporal dementia. Brain 2005, 128:1996-2005.

3. Lee SE, Rabinovici GD, Mayo MC, Wilson SM, Seeley WW, DeArmond SJ, Huang EJ, Trojanowski JQ, Growdon ME, Jang JY, Sidhu M, See TM, Karydas AM, Gorno-Tempini ML, Boxer AL, Weiner MW, Geschwind MD, Rankin KP, Miller BL: Clinicopathological correlations in corticobasal degeneration. Ann Neurol 2011, 70:327-340.

4. McMonagle P, Blair M, Kertesz A: Corticobasal degeneration and progressive aphasia. Neurology 2006, 67:1444-1451.

5. Wadia PM, Lang AE: The many faces of corticobasal degeneration. Parkinsonism Relat Disord 2007, 13:S336-S340.

6. Haug A, Boyer P, Kluger B: Diffuse lewy body disease presenting as corticobasal syndrome and progressive supranuclear palsy syndrome. Mov Disord 2013, 28:1153-1155.
7. Murray R, Neumann M, Forman MS, Farmer J, Massimo L, Rice A, Miller BL, Johnson JK, Clark CM, Hurtig HI, Gorno-Tempini ML, Lee VM, Trojanowski JQ, Grossman M: Cognitive and motor assessment in autopsy-proven corticobasal degeneration. Neurology 2007, 68:1274-1283.

8. McKeith IG, Galasko D, Kosaka K, Perry EK, Dickson DW, Hansen LA, Salmon DP, Lowe J, Mirra SS, Byrne EJ, Lennox G, Wuinn NP, Edwardson JA, Ince PG, Bergeron C, Burns A, Miller BL, Lovestone S, Collerton D, Jansen EN, Ballard C, de Vos RA, Wilcock GK, Jellinger KA, Perry RH: Consensus guidelines for the clinical and pathologic diagnosis of dementia with Lewy bodies (DLB): report of the consortium on DLB international workshop. Neurology 1996, 47:1113-1124

9. McKeith IG, Dickson DW, Lowe J, Emre M, O'Brien JT, Feldman H, Cummings J Duda JE, Lippa C, Perry EK, Aarsland D, Arai H, Ballard CG, Boeve B, Burn DJ, Costa D, Del Ser T, Dubois B, Dalasko D, Gauthier S, Goetz CG, Gomez-Tortosa E, Halliday G, Hansen LA, Hardy J, Iwatsubo T, Kalaria RN, Kaufer D, Kenny RA, Korczyn A, et al: Diagnosis and management of dementia with Lewy bodies: third report of the DLB Consortium. Neurology 2005, 65:1863-1872.

10. Mahapatra RK, Edwards MJ, Schott JM, Bhatia KP: Corticobasal degeneration. Lancet Neurol 2004, 3:736-743.

11. Grimes DA, Lang AE, Bergeron CB: Dementia as the most common presentation of cortical-basal ganglionic degeneration. Neurology 1999, 53:1969-1974.

12. McKeith IG, Ballard CG, Perry RH, Ince PG, O'Brien JT, Neill D, Lowery K, Jaros E, Barber R, Thompson P, Swann A, Fairbairn AF, Perry EK: Prospective validation of consensus criteria for the diagnosis of dementia with Lewy bodies. Neurology 2000, 54:1050-1058.

13. Lopez OL, Hamilton RL, Becker JT, Wisniewski S, Kaufer DI, Dekosky ST: Severity of cognitive impairment and the clinical diagnosis of AD with Lewy bodies. Neurology 2000, 54:1780-1787.

14. Verghese J, Crystal HA, Dickson DW, Lipton RB: Validity of clinical criteria for the diagnosis of dementia with Lewy bodies. Neurology 1999, 53:1974-1982

15. Geda YE, Boeve BF, Negash S, Graff-Radford NR, Knopman DS, Parisi JE, Dickson DW, Petersen RC: Neuropsychiatric features in 36 pathologically confirmed cases of corticobasal degeneration. J Neuropsychiatry Clin Neurosci 2007, 19:77-80.

16. McKeith I, O'Brien J: Dementia with Lewy bodies. Aust N Z J Psychiatry 1999, 33:800-808.

17. McKeith I, Del Ser T, Spano P, Emre M, Wesnes K, Anand R, Cicin-Sain A, Ferrara R, Spiegel R: Efficacy of rivastigmine in dementia with Lewy bodies: a randomised, double-blind, placebo-controlled international study. Lancet 2000, 356:2031-2036.

18. Mori E, Ikeda M, Kosaka K: Donepezil for dementia with Lewy bodies: a randomized, placebo-controlled trial. Ann Neurol 2012, 72:41-52.

19. Kerchner GA, Tartaglia MC, Boxer A: Abhorring the vacuum: use of Alzheimer's disease medications in frontotemporal dementia. Expert Rev Neurother 2011, 11:709-717.

20. Boeve BF, Lang AE, Litvan I: Corticobasal degeneration and its relationship to progressive supranuclear palsy and frontotemporal dementia. Ann Neurol 2003, 54:S15-S19.

21. Folstein MF, Folstein SE, McHugh PR: "Mini-mental state". A practical method for grading the cognitive state of patients for the clinician. J Psychiatr Res 1975, 12:189-198.

22. Mattis S: Mental status examination for organic mental syndrome in the elderly patient. In Geriatric Psychiatry. Edited by Bellak L, Karasu TB. New York: Grune \& Stratton; 1976.

23. Rouleau I, Salmon DP, Butters N, Kennedy C, McGuire K: Quantitative and qualitative analyses of clock drawings in Alzheimer's and Huntington's disease. Brain Cogn 1992, 18:70-87.

24. Blair JR, Spreen O: A revision of the National Adult Reading Test. Clin Neuropsychol 1989, 3:129-136.

25. Raven JC: Progressive Matrices. London: H.K. Lewis; 1947

26. Delis DC, Kramer JH, Kaplan E, Ober BA: California Verbal Learning Test: Adult Version. San Antonio: The Psychological Corporation; 1987.

27. Lezak M: Neuropsychological Assessment. New York: Oxford University Press; 1983.

28. Williams BW, Mack W, Henderson WW: Boston Naming Test in Alzheimer's disease. Neuropsychologia 1989, 27:1073-1079.

29. Gladsjo JA, Schuman CC, Evans JD, Peavy GM, Miller SW, Heaton RK: Norms for letter and category fluency: demographic corrections for age, education, and ethnicity. Assessment 1999, 6:147-178. 
30. Kertesz A, Poole E: The aphasia quotient: the taxonomic approach to measurement of aphasic disability. Can J Neurol Sci 1974, 1:7-16.

31. Wechsler D: Wechsler Memory Scale-Revised. San Antonio: Texas Psychological Corporation; 1987.

32. Heaton RK: Wisconsin Card Sorting Test Manual. Florida Psychological Assessment Resources: Odessa; 1981.

33. Osterrieth PA: Le test de copie d'une figure complexe. Arch Psycol 1944, 30:206-356.

34. Rey A: L'examen psychologique dans les cas d'encephalopathie traumatique. Arch Psycol 1941, 28:286-340.

35. Cummings JL: The Neuropsychiatric Inventory: assessing psychopathology in dementia patients. Neurology 1997, 48:10-16.

36. Alexopoulos GS, Abrams RC, Young RC, Shamoian CA: Cornell scale for depression in dementia. Biol Psychiatry 1988, 23:271-284.

37. Gelinas I, Gauthier L, McIntyre M, Gauthier S: Development of a functional measure for persons with Alzheimer's disease: the disability assessment for dementia. Am J Occup Ther 1999, 53:471-481.

38. Matsuda H, Yagishita A, Tsuji S, Hisada K: A quantitative approach to technetium-99 m ethyl cysteinate dimer: a comparison with technetium-99 m hexamethylpropylene amine oxime. Eur J Nucl Med 1995, 22:633-637.

39. Kovacevic N, Lobaugh NJ, Bronskill MJ, Levine B, Feinstein A, Black SE: A robust method for extraction and automatic segmentation of brain images. Neuroimage 2002, 17:1087-1100.

40. Ramirez J, Gibson E, Quddus A, Lobaugh NJ, Feinstein A, Levine B, Scott CJ Levy-Cooperman N, Gao FQ, Black SE: Lesion Explorer: a comprehensive segmentation and parcellation package to obtain regional volumetrics for subcortical hyperintensities and intracranial tissue. Neuroimage 2011, 54:963-973.

41. Woolrich MW, Jbabdi S, Patenaude B, Chappell M, Makni S, Behrens T, Beckmann C, Jenkinson M, Smith SM: Bayesian analysis of neuroimaging data in FSL. Neuroimage 2009, 45:S173-S186.

42. Fischl B, Salat DH, Busa E, Albert M, Dieterich M, Haselgrove $C$, van der Kouwe A, Killiany R, Kennedy D, Klaveness S, Montillo A, Makris N, Rosen B, Dale AM: Whole brain segmentation: automated labeling of neuroanatomical structures in the human brain. Neuron 2002, 33:341-355.

43. Fischl B, Dale AM: Measuring the thickness of the human cerebral cortex from magnetic resonance images. Proc Natl Acad Sci U S A 2000, 97:11050-11055.

44. Desikan RS, Segonne F, Fischl B, Quinn BT, Dickerson BC, Blacker D, Buckner RL, Dale AM, Maguire RP, Hyman BT, Albert MS, Killiany RJ: An automated labeling system for subdividing the human cerebral cortex on MRI scans into gyral based regions of interest. Neuroimage 2006, 31:968-980.

45. Stamatakis EA, Wilson JT, Wyper DJ: Spatial normalization of lesioned HMPAO-SPECT images. Neuroimage 2001, 14:844-852.

46. Colloby SJ, Fenwick JD, Williams ED, Paling SM, Lobotesis K, Ballard C, McKeith I, O'Brien JT: A comparison of (99 m)Tc-HMPAO SPET changes in dementia with Lewy bodies and Alzheimer's disease using statistical parametric mapping. Eur J Nucl Med Mol Imaging 2002, 29:615-622.

47. Worsley KJ, Marrett S, Neelin P, Vandal AC, Friston KJ, Evans AC: A unified statistical approach for determining significant signals in images of cerebral activation. Hum Brain Mapp 1996, 4:58-73.

48. Genovese CR, Lazar NA, Nichols T: Thresholding of statistical maps in functional neuroimaging using the false discovery rate. Neuroimage 2002, 15:870-878.

49. Lacadie CM, Fulbright RK, Rajeevan N, Constable RT, Papademetris X: More accurate Talairach coordinates for neuroimaging using non-linear registration. Neuroimage 2008, 42:717-725.

50. The Yale Non-linear MNI to Talairach Converter. [http://noodle.med.yale. edu/ papad/mni2tal//

51. Lancaster JL, Woldorff MG, Parsons LM, Liotti M, Freitas CS, Rainey L, Kochunov PV, Nickerson D, Mikiten SA, Fox PT: Automated Talairach atlas labels for functional brain mapping. Hum Brain Mapp 2000, 10:120-131.

52. Talairach Daemon Client [http://talairach.org/client.html]

53. Lobaugh NJ, Caldwell CB, Black SE, Leibovitch FS, Swartz RH: Three brain SPECT region-of-interest templates in elderly people: normative values, hemispheric asymmetries, and a comparison of single- and multihead cameras. J Nucl Med 2000, 41:45-56.

54. Van Laere K, Versijpt J, Audenaert K, Koole M, Goethals I, Achten E, Dierckx R: 99mTc-ECD brain perfusion SPET: variability, asymmetry and effects of age and gender in healthy adults. Eur J Nucl Med 2001, 28:873-887.

55. Armstrong MJ, Litvan I, Lang AE, Bak TH, Bhatia KP, Borroni B, Boxer AL, Dickson DW, Grossman M, Hallett M, Josephs KA, Kertesz A, Lee SE,
Miller BL, Reich SG, Riley DE, Tolosa E, Troester A, Vidailhet M, Weiner WJ: Criteria for the diagnosis of corticobasal degeneration. Neurology 2013, 80:496-503

56. Masellis M, Momeni $P$, Meschino W, Heffner R Jr, Elder J, Sato C, Liang Y, St George-Hyslop P, Hardy J, Bilbao J, Black S, Rogaeva E: Novel splicing mutation in the progranulin gene causing familial corticobasal syndrome. Brain 2006, 129:3115-3123.

57. Calderon J, Perry RJ, Erzinclioglu SW, Berrios GE, Dening TR, Hodges JR: Perception, attention, and working memory are disproportionately impaired in dementia with Lewy bodies compared with Alzheimer's disease. J Neurol Neurosurg Psychiatry 2001, 70:157-164

58. Frasson E, Moretto G, Beltramello A, Smania N, Pampanin M, Stegagno C, Tanel R, Rizzuto N: Neuropsychological and neuroimaging correlates in corticobasal degeneration. Ital J Neurol Sci 1998, 19:321-328.

59. Huey ED, Goveia EN, Paviol S, Pardini M, Krueger F, Zamboni G, Tierney MC, Wassermann EM, Grafman J: Executive dysfunction in frontotemporal dementia and corticobasal syndrome. Neurology 2009, 72:453-459.

60. Moreaud $\mathrm{O}$, Naegele B, Pellat J: The nature of apraxia in corticobasal degeneration: a case of melokinetic apraxia. Cogn Behav Neurol 1996, 9:288-292.

61. Collerton D, Burn D, McKeith I, O'Brien J: Systematic review and meta-analysis show that dementia with Lewy bodies is a visual-perceptual and attentional-executive dementia. Dement Geriatr Cogn Disord 2003, 16:229-237.

62. Cormack F, Aarsland D, Ballard C, Tovee MJ: Pentagon drawing and neuropsychological performance in Dementia with Lewy Bodies, Alzheimer's disease, Parkinson's disease and Parkinson's disease with dementia. Int J Geriatr Psychiatry 2004, 19:371-377.

63. Noe E, Marder K, Bell KL, Jacobs DM, Manly JJ, Stern Y: Comparison of dementia with Lewy bodies to Alzheimer's disease and Parkinson's disease with dementia. Mov Disord 2004, 19:60-67.

64. Bak TH, Caine D, Hearn VC, Hodges JR: Visuospatial functions in atypical parkinsonian syndromes. J Neurol Neurosurg Psychiatry 2006, 77:454-456.

65. Soliveri P, Monza D, Paridi D, Radice D, Grisoli M, Testa D, Savoiardo M, Girotti F: Cognitive and magnetic resonance imaging aspects of corticobasal degeneration and progressive supranuclear palsy. Neurology 1999, 53:502-507.

66. Elwood RW: The California verbal learning test: psychometric characteristics and clinical application. Neuropsychol Rev 1995, 5:173-201.

67. Eidelberg D, Dhawan V, Moeller JR, Sidtis JJ, Ginos JZ, Strother SC, Cederbaum J, Greene P, Fahn S, Powers JM, Rottenburg DA: The metabolic landscape of cortico-basal ganglionic degeneration: regional asymmetries studied with positron emission tomography. J Neurol Neurosurg Psychiatry 1991, 54:856-862.

68. Garraux G, Salmon E, Peigneux P, Kreisler A, Degueldre C, Lemaire C, Destee A, Franck G: Voxel-based distribution of metabolic impairment in corticobasal degeneration. Mov Disord 2000, 15:894-904.

69. Markus HS, Lees AJ, Lennox G, Marsden CD, Costa DC: Patterns of regional cerebral blood flow in corticobasal degeneration studied using HMPAO SPECT; comparison with Parkinson's disease and normal controls. Mov Disord 1995, 10:179-187.

70. Okuda B, Tachibana H, Kawabata K, Takeda M, Sugita M: Cerebral blood flow correlates of higher brain dysfunctions in corticobasal degeneration. J Geriatr Psychiatry Neurol 1999, 12:189-193.

71. Zhang L, Murata Y, Ishida R, Saitoh Y, Mizusawa H, Shibuya H: Differentiating between progressive supranuclear palsy and corticobasal degeneration by brain perfusion SPET. Nucl Med Commun 2001, 22:767-772

72. Lobotesis K, Fenwick JD, Phipps A, Ryman A, Swann A, Ballard C, McKeith IG, O'Brien JT: Occipital hypoperfusion on SPECT in dementia with Lewy bodies but not AD. Neurology 2001, 56:643-649.

73. Okuda B, Tachibana H, Kawabata K, Takeda M, Sugita M: Comparison of brain perfusion in corticobasal degeneration and Alzheimer's disease. Dement Geriatr Cogn Disord 2001, 12:226-231.

74. Albin RL, Minoshima S, D'Amato CJ, Frey KA, Kuhl DA, Sima AA: Fluorodeoxyglucose positron emission tomography in diffuse Lewy body disease. Neurology 1996, 47:462-466.

75. Imamura T, Ishii K, Sasaki M, Kitagaki H, Yamaji S, Hirono N, Shimomura T, Hashimoto M, Tanimukai S, Kazui H, Mori E: Regional cerebral glucose metabolism in dementia with Lewy bodies and Alzheimer's disease: a comparative study using positron emission tomography. Neurosci Lett 1997, 235:49-52. 
76. Higuchi M, Tashiro M, Arai H, Okamura N, Hara S, Higuchi S, Itoh M, Shin RW, Trojanowski JQ, Sasaki H: Glucose hypometabolism and neuropathological correlates in brains of dementia with Lewy bodies. Exp Neurol 2000, $162: 247-256$.

77. Ishii K, Imamura T, Sasaki M, Yamaji S, Sakamoto S, Kitagaki H, Hashimoto M, Hirono N, Shimomura T, Mori E: Regional cerebral glucose metabolism in dementia with Lewy bodies and Alzheimer's disease. Neurology 1998, 51:125-130.

78. Minoshima S, Foster NL, Sima AA, Frey KA, Albin RL, Kuhl DE: Alzheimer's disease versus dementia with Lewy bodies: cerebral metabolic distinction with autopsy confirmation. Ann Neurol 2001, 50:358-365.

79. Varma AR, Talbot PR, Snowden JS, Lloyd JJ, Testa HJ, Neary D: A 99mTcHMPAO single-photon emission computed tomography study of Lewy body disease. J Neurol 1997, 244:349-359.

80. Koyama M, Kawashima R, Ito H, Ono S, Sato K, Goto R, Kinomura S, Yoshioka $\mathrm{S}$, Sato T, Fukuda H: SPECT imaging of normal subjects with technetium99 m-HMPAO and technetium-99 m-ECD. J NuCl Med 1997, 38:587-592.

81. Pasquier J, Michel BF, Brenot-Rossi I, Hassan-Sebbag N, Sauvan R, Gastaut JL: Value of (99 m)Tc-ECD SPET for the diagnosis of dementia with Lewy bodies. Eur J Nucl Med Mol Imaging 2002, 29:1342-1348.

82. Ishii K, Yamaji S, Kitagaki H, Imamura T, Hirono N, Mori E: Regional cerebral blood flow difference between dementia with Lewy bodies and AD. Neurology 1999, 53:413-416.

83. Law I, Svarer C, Rostrup E, Paulson OB: Parieto-occipital cortex activation during self-generated eye movements in the dark. Brain 1998, 121:2189-2200.

84. Haldane M, Cunningham G, Androutsos C, Frangou S: Structural brain correlates of response inhibition in Bipolar Disorder I. J Psychopharmacol 2008, 22:138-143.

85. Bluhm RL, Clark CR, McFarlane AC, Moores KA, Shaw ME, Lanius RA: Default network connectivity during a working memory task. Hum Brain Mapp 2011, 32:1029-1035.

86. Zhang S, Li CS: Functional networks for cognitive control in a stop signal task: independent component analysis. Hum Brain Mapp 2012, 33:89-104.

87. Bogousslavsky J, Miklossy J, Deruaz JP, Assal G, Regli F: Lingual and fusiform gyri in visual processing: a clinico-pathologic study of superior altitudinal hemianopia. J Neurol Neurosurg Psychiatry 1987, 50:607-614.

88. Machielsen WC, Rombouts SA, Barkhof F, Scheltens P, Witter MP: FMRI of visual encoding: reproducibility of activation. Hum Brain Mapp 2000, 9:156-164.

89. Howard D, Patterson K, Wise R, Brown WD, Friston K, Weiller C, Frackowiak $R$ : The cortical localization of the lexicons. Positron emission tomography evidence. Brain 1992, 115:1769-1782.

90. Mechelli A, Humphreys GW, Mayall K, Olson A, Price CJ: Differential effects of word length and visual contrast in the fusiform and lingual gyri during reading. Proc Biol Sci 2000, 267:1909-1913.

91. Hsu NS, Frankland SM, Thompson-Schill SL: Chromaticity of color perception and object color knowledge. Neuropsychologia 2012, 50:327-333.

92. Wang X, Han Z, He Y, Caramazza A, Song L, Bi Y: Where color rests: spontaneous brain activity of bilateral fusiform and lingual regions predicts object color knowledge performance. Neuroimage 2013, 76:252-263.

93. Grill-Spector K, Kourtzi Z, Kanwisher N: The lateral occipital complex and its role in object recognition. Vision Res 2001, 41:1409-1422.

94. Gabryelewicz T, Masellis M, Berdynski M, Bilbao JM, Rogaeva E, St George-Hyslop P, Barczak A, Czyzewski K, Barcikowska M, Wszolek Z, Black SE, Zekanowski C: Intra-familial clinical heterogeneity due to FTLD-U with TDP-43 proteinopathy caused by a novel deletion in progranulin gene (PGRN). J Alzheimers Dis 2010, 22:1123-1133.

95. Gregory CA, Serra-Mestres J, Hodges JR: Early diagnosis of the frontal variant of frontotemporal dementia: how sensitive are standard neuroimaging and neuropsychologic tests? Neuropsychiatry Neuropsychol Behav Neurol 1999, 12:128-135.

96. Mendez MF, Shapira JS, McMurtray A, Licht E, Miller BL: Accuracy of the clinical evaluation for frontotemporal dementia. Arch Neurol 2007, 64:830-835

\section{doi:10.1186/s13195-014-0071-4}

Cite this article as: Misch et al: Differentiating between visual hallucination-free dementia with Lewy bodies and corticobasal syndrome on the basis of neuropsychology and perfusion single-photon emission computed tomography. Alzheimer's Research \& Therapy 2014 6:71.

\section{Submit your next manuscript to BioMed Central and take full advantage of:}

- Convenient online submission

- Thorough peer review

- No space constraints or color figure charges

- Immediate publication on acceptance

- Inclusion in PubMed, CAS, Scopus and Google Scholar

- Research which is freely available for redistribution 